\title{
Assessment of the Quorum Sensing Inhibition Activity of a Non-Toxic Chitosan in an N-Acyl Homoserine Lactone (AHL)-Based Escherichia coli Biosensor
}

\author{
Xiaofei Qin ${ }^{1}$, Jana Emich 1,2 (D) and Francisco M. Goycoolea 1,3,* (i) \\ 1 Institute of Plant Biology and Biotechnology, University of Münster, Schlossplatz 8, \\ 48143 Münster, Germany; qxf200459420@163.com (X.Q.); jana.emich@wwu.de (J.E.) \\ 2 Institute of Human Genetics, University Hospital Münster, Vesaliusweg 12-14, 48149 Münster, Germany \\ 3 School of Food Science and Nutrition, University of Leeds, Leeds LS2 9JT, UK \\ * Correspondence: F.M.Goycoolea@leeds.ac.uk; Tel.: +44-113-343-1412
}

Received: 20 July 2018; Accepted: 27 August 2018; Published: 4 September 2018

\begin{abstract}
New approaches to deal with drug-resistant pathogenic bacteria are urgent. We studied the antibacterial effect of chitosans against an Escherichia coli quorum sensing biosensor reporter strain and selected a non-toxic chitosan to evaluate its quorum sensing (QS) inhibition activity and its effect on bacterial aggregation. To this end, chitosans of varying degree of acetylation (DA) (12 to $69 \%)$ and molecular weight $\left(M_{w}\right)(29$ to $288 \mathrm{kDa})$ were studied. Only chitosans of low DA $(\sim 12 \%)$ inhibited bacterial growth, regardless of their $M_{w}$. A chitosan with medium degree of polymerization (named MDP) DA30, with experimental DA $42 \%$ and $M_{w} 115 \mathrm{kDa}$ was selected for further QS inhibition and scanning electron microscopy (SEM) imaging studies. MDP DA30 chitosan exhibited QS inhibition activity in an inverse dose-dependent manner $(\leq 12.5 \mu \mathrm{g} / \mathrm{mL})$. SEM images revealed that this chitosan, when added at low concentration $(\leq 30.6 \mu \mathrm{g} / \mathrm{mL})$, induced substantial bacterial aggregation, whereas at high concentration $(234.3 \mu \mathrm{g} / \mathrm{mL})$, it did not. Aggregation explains the QS inhibition activity as the consequence of retardation of the diffusion of $N$-acylated homoserine lactones (AHLs).
\end{abstract}

Keywords: chitosan; quorum sensing; antibacterial activity; quorum sensing inhibition

\section{Introduction}

Chitin, poly $(\beta-(1 \rightarrow 4)-N$-acetyl-D-glucosamine), is the second most abundant polymer in the biosphere. It occurs in the exoskeletons of crustaceans and insects, in squid pens, the cell walls of fungi, and in diatoms, amongst other organisms. Currently, chitin is sourced at an industrial scale from shrimp and crab shell waste. Chitosan is a linear polycationic heteropolysaccharide biopolymer that is produced by partial alkaline $N$-deacetylation of chitin [1]. It is mainly composed of two kinds of $\beta$-(1-4)-linked structural units, namely 2-amino-2-deoxy-D-glucose and $\mathrm{N}$-acetyl-amino-2-deoxy-D-glucose. However, since it is technically difficult to completely deacetylate chitin and since highly deacetylated chitosan can be re-acetylated, what is usually known as 'chitosan' rather refers to a family of polysaccharides with different degrees of acetylation and polymerization. Therefore, it is best to refer to this family of polymers as 'chitosans'. The capacity of chitosans to dissolve in aqueous solutions is the commonly-accepted criterion to differentiate them from chitin. Chitosan when dissolved in dilute aqueous acid solutions behaves as a weak polybase with a $\mathrm{pK}_{0}$ of $6.1 \pm 0.1$ [2], namely in acetic, formic, succinic, lactic, and hydrochloric acid. The characteristics of a chitosan are mostly defined by its molar mass $\left(M_{w}\right)$ given by the degree of polymerization (DP), its degree of acetylation (DA) and its pattern of acetylation (PA). There is no precise criterion to distinguish chitosan polymers from oligomers. The DP can vary over a wide range of $\sim 20$ to $\gtrsim 1000 \mathrm{kDa}$; 
the DA from 0 up to $\sim 70 \%$, and the PA from purely random to blockwise. The variation in these three parameters gives rise to a vast number of different possible chitosans.

Research on chitosans has burgeoned in recent decades due to the large number of material and bioactive properties-namely antimicrobial [3-9], anti-inflammatory [10], mucoadhesive [11,12], and immuno-adjuvant effects [13] —as well as the capacity to complex and condense nucleic acids [14], among others. A broad-spectrum antibacterial activity of chitosans in solution, or as nano- and microparticles or films, has been demonstrated against Gram-positive and Gram-negative bacteria $[7,15-20]$. The antimicrobial properties of chitosans have found applications in the food industry, as a pharmaceutical agent in the medical industry, in the textile industry, in cosmetics, in agriculture, and in wastewater purification $[1,5,15]$. Despite the enormous amount of research and published literature on the antibacterial and other effects of chitosan on eukaryotic cells, in general, there is lack of experimental reproducibility and often the results are discrepant. To a great deal, this is the consequence of the poor characterization or documentation of the characteristics of the used chitosan samples.

Antibiotic resistance is a serious problem that currently poses major unmet challenges and gaps in global health [21]. There are several mechanisms whereby bacteria are intrinsically resistant or acquire resistance to antibiotic treatment. They can inhibit the antibiotic's access to drug targets, change the structure of antibiotic targets, or directly modify the antibiotics to inactivate them [21]. Nowadays, it is urgent to pursue alternative strategies for the control of bacterial infections. Quorum sensing (QS) is a form of cell density-dependent bacterial gene expression regulation mechanism controlled by a chemically exquisite signaling system that affects communal traits (e.g., biofilm formation, bioluminescence, motility, toxin production) in both Gram-negative and Gram-positive bacteria [22]. In a large number of Gram-negative species, QS is mediated by conserved small-molecule signals that act as autoinducers, termed acylated homoserine lactones (AHLs). At high cell densities, AHLs can bind to specific receptors that act as transcriptional activators of the gene cascades involved in virulence responses [22,23]. Hence, inhibition of QS can be considered a promising novel strategy to deal with bacterial pathogens at large scale while potentially circumventing the problem of antibiotic resistance development [24].

So far, the antimicrobial activity of chitosans has been extensively studied, but only limited information focuses on the effect of chitosans on bacterial QS activity. To the best of our knowledge, only one recent paper has reported that chitosans showed potential to disturb biofilm formation by QS inhibition and to inhibit Chromobacterium violaceum violacein production [25]. In two parallel studies conducted in our laboratories [26,27], we have documented the QS-inhibiting effect of both chitosan oil-core nanocapsules and chitosan-based crosslinked matrix nanoparticles. In the present work, complementary to the two parallel ones, we have investigated the antibacterial activity of 10 chitosan samples of varying $M_{w}$ and DA. This enabled us to select one non-toxic chitosan to explore in further detail its anti-QS activity using the Escherichia coli Top10 reporter strain that we have used in previous works [26,28-30].

\section{Materials and Methods}

\subsection{Materials}

The parent chitosan with a molecular weight of $288 \mathrm{kDa}$ and DA of $16 \%$ was purchased from Mahtani Chitosan Pvt. Ltd (Veraval, India; brand nam: Chitosan 132; batch No. SCCF 20140609). The chitosan samples were all derived from the same parent chitosan. They were depolymerized and, if needed, re-acetylated before purification. This work was conducted in our laboratory according to the methods described in our previous study [31]. The DA was determined by proton nuclear magnetic resonance spectroscopy $\left({ }^{1} \mathrm{H} N M R\right)$ by dissolving the chitosans in deuterium oxide $\left(\mathrm{D}_{2} \mathrm{O}\right)$ with deuterium chloride ( $\mathrm{DCl}$ ) (at pD 3-4) according to the method by Lavertu et al. [32]. The molecular weight distribution and corresponding $M_{w}, M_{n}$, and polydispersity index $\left(I_{p}\right)$ parameters were 
determined via HPSEC-MALLS-DRI (Polymer Standards Service GmbH (PSS), Mainz, Germany) using an Agilent 1200 system with isocratic pump and Novema columns (30,3000, and $3000 \AA$ and guard column; I.D.: $8 \mathrm{~mm}$; PSS) coupled online with a refractive index detector (Agilent 1200 RID, Santa Rosa, CA, USA) and multi-angle-laser-light-scattering (SLD 7000 MALLS, Brookhaven Instruments, Warwick, UK) equipped with a $5 \mathrm{~mW} \mathrm{He} / \mathrm{Ne}$ laser operating at $\lambda=632.8 \mathrm{~nm}$. The degassed mobile phase consisted of ammonium acetate $0.2 \mathrm{M}$ /acetic acid $0.15 \mathrm{M}$ buffer $\mathrm{pH} 4.5$ at a flow rate of $0.7 \mathrm{~mL} / \mathrm{min}$ at $35^{\circ} \mathrm{C}$. Data was evaluated using the software WinGPC 7.0.1 (PSS). Chitosans with $M_{w}$ from $\sim 185$ to $\sim 288$, from $\sim 85$ to $\sim 115$, and from $\sim 29$ to $\sim 58 \mathrm{kDa}$ were regarded here as of high (HDP), medium (MDP), or low degree of polymerization (LDP), respectively. The rest of the identification code was obtained from the DA value (e.g., HDP DA12, etc.). N-(3-oxohexanoyl)-L-homoserine lactone $\left(3 \mathrm{OC}_{6} \mathrm{HSL}\right)$ and all other chemicals were of analytical grade and purchased from Sigma (Sigma-Aldrich, Hamburg, Germany), unless stated otherwise. The overall methodological approach adopted in this work is illustrated in Scheme 1.

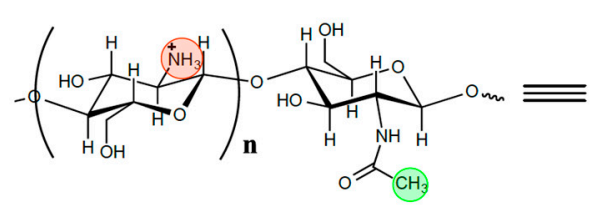

Same $\left[\mathrm{NH}_{3}{ }^{+}\right]$charge equivalent concentration of chitosans of varying DA and $\mathrm{Mw}$

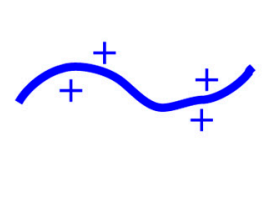

$\mathrm{CFU}$ assay and
microtiter plate assay

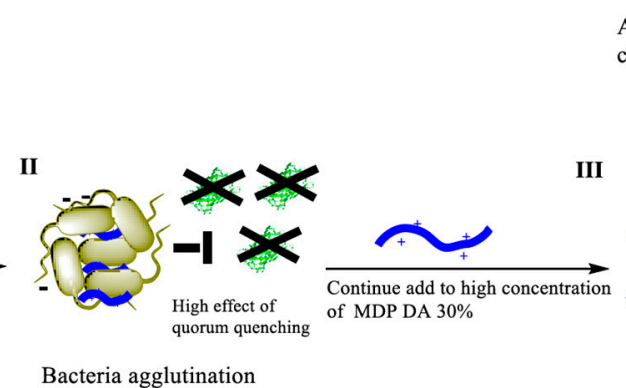

Bacteria agglutination
II
I

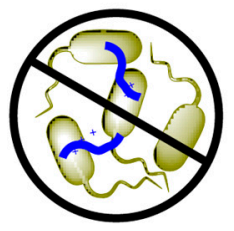

Antibacterial activity: chitosan low DA (DA 12\%)
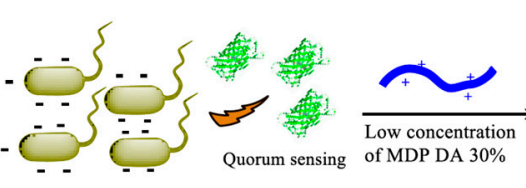

III

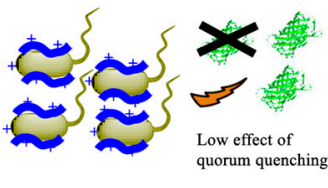

Bacteria repulsion

Scheme 1. Experimental approach used to screen the chitosans with highest antibacterial activity, namely chitosans of low, medium or high degree of polymerization (DP) and low degree of acetylation (DA, 12\%) (Step I). A non-antibacterial chitosan termed MDP DA 30 with medium degree of polymerization (MDP) and an experimental DA of 40\% was selected for quorum sensing inhibition activity and agglutination assays at low (Step II) or high (Step III) concentrations. CFU: colony forming unit.

\subsection{Chitosan Sample Preparation}

The chitosan samples in powder form were fully dissolved in aqueous $5 \%$ stoichiometric excess of hydrochloric acid by gentle magnetic stirring $(\sim 10 \mathrm{~h})$. In order to test the antibacterial activity of different chitosan samples, the same concentration of amino groups of chitosan was prepared and applied in this assay. The final concentration of amino groups was defined as 0.389 or $0.778 \mathrm{mM}$ for all samples. However, the mass concentrations of samples were different according to the DA as shown in Table 1.

\subsection{Bacterial Strains}

Escherichia coli Top10 was transformed with the plasmid pSB1A3-BBa_T9002, carrying the BBa_T9002 genetic device (Registry of Standard Biological Parts: http:/ / parts.igem.org/Part:BBa_ T9002), kindly donated by Prof. Anderson Lab (UC Berkeley, CA, USA). The sequence BBa_T9002 was introduced by chemical transformation (Invitrogen, Life Technologies Co, Glasgow, UK) and stored as a $30 \%$ glycerol stock at $-80{ }^{\circ} \mathrm{C}$. The transformed strain is a biosensor that can respond to the 3OC6HSL and is the same strain used in accompanying studies [33]. The sequence BBa_T9002 
comprises the transcription factor (LuxR) under the control of the lux pR promoter from Vibrio fischeri, which is constitutively expressed but is active only in the presence of the exogenous cell-cell signaling molecule 3OC6HSL.

\subsection{Growth Media and Conditions}

Bacterial strains were cultivated in Luria-Bertani (LB) and M9 minimal medium purchased from Becton, Dickinson \& Co, Kehl, Germany. Ten milliliters of LB broth supplemented with $200 \mu \mathrm{g} / \mathrm{mL}$ ampicillin was inoculated with a single colony from a freshly streaked plate of Top10 containing BBa_T9002 and incubated for $18 \mathrm{~h}$ at $37^{\circ} \mathrm{C}$, shaking at $100 \mathrm{rpm}$. Each culture was then diluted 1:1000 into $20 \mathrm{~mL}$ M9 minimal medium supplemented with $0.2 \%$ casamino acids and $1 \mathrm{mM}$ thiamine hydrochloride plus $200 \mu \mathrm{g} / \mathrm{mL}$ ampicillin (AppliChem GmbH, Darmstadt, Germany). The culture was maintained under the same conditions until the optical density measured at $600 \mathrm{~nm}\left(\mathrm{OD}_{600}\right)$ reached $0.15(\sim 5 \mathrm{~h})$. Then $500 \mu \mathrm{L}$ overnight culture and $500 \mu \mathrm{L} \mathrm{30 \%} \mathrm{sterile} \mathrm{glycerol} \mathrm{were} \mathrm{mixed} \mathrm{together} \mathrm{in}$ cryotubes and stored at $-80^{\circ} \mathrm{C}$. Before the biosensor assay was conducted, $40 \mu \mathrm{L}$ bacteria from the glycerol stock vials was cultivated in $20 \mathrm{~mL} \mathrm{M9}$ medium plus $200 \mu \mathrm{g} / \mathrm{mL}$ ampicillin until the OD $_{600}$ reached $0.04 \sim 0.07(\sim 4 \mathrm{~h})$.

Table 1. Characteristics of chitosan samples.

\begin{tabular}{|c|c|c|c|c|c|}
\hline Chitosan Name & $M_{w}(k D a)^{1}$ & $I_{p}{ }^{1}$ & Calculated DA (\%) ${ }^{2}$ & Experimental DA $(\%)^{3}$ & Chitosan Concentration in Antibacterial Bioassays $(\mu \mathrm{g} / \mathrm{mL})^{4}$ \\
\hline LDP DA12 & 29 & 1.6 & 12 & 12 & 73.5 \\
\hline LDP DA20 & 35 & 2.1 & 20 & n.a & 82.5 \\
\hline LDP DA30 & 37 & 1.7 & 30 & n.a & 96.7 \\
\hline LDP DA40 & 58 & 2 & 40 & 44 & 115.6 \\
\hline LDP DA60 & n.a & n.a & 60 & 69 & 181.7 \\
\hline MDP DA12 & 85 & 1.6 & 12 & 14 & 73.5 \\
\hline MDP DA30 & 115 & 1.7 & 30 & 42 & 96.7 \\
\hline MDP DA50 & 91 & 2.5 & 50 & n.a & 142.0 \\
\hline HDP DA12 & 288 & 2.1 & 12 & 16 & 73.5 \\
\hline HDP DA60 & 185 & 1.9 & 60 & 68 & 181.7 \\
\hline
\end{tabular}

${ }^{1}$ Weight average molecular weight $\left(M_{w}\right)$ and polydispersity index $\left(I_{p}=M_{w} / M_{n}\right)$ values as determined by high performance size exclusion chromatography with multi-angle laser light scattering and differential refractive index detection (HPSEC-MALLS-DRI); ${ }^{2}$ degree of acetylation (\%) values as estimated from the stoichiometry of the $\mathrm{N}$-acetylation reaction; ${ }^{3}$ experimental DA (\%) values as determined by proton nuclear magnetic resonance spectroscopy $\left({ }^{1} \mathrm{H} \mathrm{NMR}\right) ;{ }^{4}$ concentration $(\mu \mathrm{g} / \mathrm{mL})$ equivalent to $0.389 \mathrm{mM}\left[-\mathrm{NH}_{3}{ }^{+}\right]$molar charge; n.a. $=$data not available.

\subsection{Assays for the Determination of Antibacterial Activity}

The antibacterial activity of the chitosans was tested by two different methods. The first one consisted in recording the time evolution of the absorbance intensity $\left(\lambda=600 \mathrm{~nm}, \mathrm{OD}_{600}\right)$ during the incubation of $E$. coli in culture medium. Briefly, bacteria were cultivated in M9 medium to reach an $\mathrm{OD}_{600}$ of $\sim 0.04-0.07$. In a flat-bottomed 96-well-plate (Greiner Bio-One International GmbH, Kremsmünster, Austria), a $180 \mu \mathrm{L}$ aliquot of E. coli culture was mixed with $20 \mu \mathrm{L}$ of the different chitosan solutions with final equimolar amine group concentrations of $0.389 \mathrm{mM}$. As the control, $20 \mu \mathrm{L}$ of the chitosan solutions were mixed with $180 \mu \mathrm{L}$ M9 medium. Three different blanks were also prepared, namely $180 \mu \mathrm{L}$ E. coli mixed with $20 \mu \mathrm{L}$ water as a negative control, $180 \mu \mathrm{L}$ M9 medium with $20 \mu \mathrm{L}$ water to measure the absorbance background, and $180 \mu \mathrm{L}$ E. coli supplied with $20 \mu \mathrm{L}$ kanamycin (AppliChem, $0.5 \mathrm{mg} / \mathrm{mL}$ ) as a positive control. The $\mathrm{OD}_{600}$ of the microtiter plate was measured with a Safire Tecan-F129013 Microplate Reader (Tecan, Crailsheim, Germany) every $158 \mathrm{~s}$ for 60 cycles (2:38 h total time) at $37^{\circ} \mathrm{C}$. Afterwards, aliquots of $20 \mu \mathrm{L}$ were sampled from the microplate wells and remixed with fresh M9 medium to be subjected to the same measurement cycles again. Data was processed with XFLUOR4 version 4.51 and corrected by subtracting the corresponding chitosan control and the difference between the bacterial blank and the medium blank. The growth rate of controls and samples was obtained and analyzed from the original data. Using a log-linear model to regress $\mathrm{OD}_{600}\left(\log _{0}\right.$ phase) with respect to time $(0-100 \mathrm{~min})$, the growth rate of $\mathrm{OD}_{600}$ was obtained directly from the slope 
of the estimated regression equation. Relative data was expressed as the ratio of each measurement to the corresponding control.

The second assay aimed to estimate the number of colony forming units (CFUs) of E. coli under the influence of chitosans. To this end, a culture was prepared by mixing $20 \mathrm{~mL} \mathrm{LB}$ medium, $20 \mu \mathrm{L}$ ampicillin $(200 \mu \mathrm{g} / \mathrm{mL}$, AppliChem), and $40 \mu \mathrm{L}$ of E. coli glycerol stock and incubating it overnight at $37{ }^{\circ} \mathrm{C}$ with shaking at $100 \mathrm{rpm}$. The $\mathrm{OD}_{600}$ was adjusted to $\sim 0.1$ using LB medium, and $180 \mu \mathrm{L}$ of the diluted E. coli culture was incubated with $20 \mu \mathrm{L}$ of each chitosan solution of identical equivalent charge concentration $(0.389$ or $0.778 \mathrm{mM})$ in a 96 -well-plate at $37^{\circ} \mathrm{C}$ and $100 \mathrm{rpm}$ for $1 \mathrm{~h}$. Afterwards, serial dilution was performed with $180 \mu \mathrm{L}$ M9 medium. Then, all the dilutions were plated on LB-ampicillin-agar-plates by adding a drop of $10 \mu \mathrm{L}$. Plates were incubated overnight at $37^{\circ} \mathrm{C}$ and colonies were counted the next day. A weighted average was calculated from the dilutions.

\subsection{Escherichia coli Top10 Biosensor Assay}

The $3 \mathrm{OC}_{6} \mathrm{HSL}$ was dissolved in acetonitrile to a stock concentration of $100 \mathrm{mM}$ and stored at $20{ }^{\circ} \mathrm{C}$. Prior to each experiment, serial dilutions from the stock solution were prepared in water to produce solutions with a concentration ranging from $100 \mathrm{mM}$ to $10 \mathrm{nM}$. For a typical biosensor assay, $40 \mu \mathrm{L}$ of the bacterial glycerol stock were cultivated with $20 \mathrm{~mL}$ M9 medium supplemented with $200 \mu \mathrm{g} / \mathrm{mL}$ ampicillin up to an $\mathrm{OD}_{600}$ of 0.04 to $0.07(\sim 4 \mathrm{~h})$. Bacterial growth was monitored by measuring the optical density at $\lambda=600 \mathrm{~nm}\left(\mathrm{OD}_{600}\right)$ on a Microplate Reader Safire F129013 (Tecan, Crailsheim, Germany).

We then mixed $10 \mu \mathrm{L} 3 \mathrm{OC}_{6} \mathrm{HSL}$ solution with $10 \mu \mathrm{L}$ of the MDP DA $42 \%$ chitosan at varying concentrations $(1.25,2.5,4.17,8.33,12.5,25$, and $50 \mu \mathrm{g} / \mathrm{mL})$ in the wells of a flat-bottomed 96-well plate (Greiner Bio-One, cat. \# M3061) and each well was filled with $180 \mu \mathrm{L}$ aliquots of the bacterial culture to test for QS inhibition activity. Several controls were set up. Blank 1 wells contained $180 \mu \mathrm{L}$ of M9 medium and $20 \mu \mathrm{L}$ of milliQ water to measure the absorbance background. Blank 2 wells contained $180 \mu \mathrm{L}$ of bacterial culture and $20 \mu \mathrm{L}$ of milliQ water to measure the absorbance background corrected for the cells. Finally, positive control wells contained $10 \mu \mathrm{L}$ of water plus $10 \mu \mathrm{L} 3 \mathrm{OC}_{6} \mathrm{HSL}_{\text {solution and }}$ $180 \mu \mathrm{L}$ of bacterial culture to measure the fluorescence background. To remove any contribution of $3 \mathrm{OC}_{6} \mathrm{HSL}$ itself to the $\mathrm{OD}_{600}$ and fluorescence intensity measurements, another control consisted of $10 \mu \mathrm{L} 3 \mathrm{OC}_{6} \mathrm{HSL}$ solution with $10 \mu \mathrm{L}$ of the samples in the wells and each well was then filled with $180 \mu \mathrm{L}$ M9 medium.

The plates were incubated in a Safire Tecan-F129013 Microplate Reader (Tecan) at $37{ }^{\circ} \mathrm{C}$ and fluorescence measurements $\left(\lambda_{\mathrm{ex}}=480 \mathrm{~nm}\right.$ and $\lambda_{\mathrm{em}}=510 \mathrm{~nm}, 40 \mu \mathrm{s}, 10$ flashes, gain 100, top fluorescence) were conducted every $6 \mathrm{~min}$, along with absorbance measurements $\left(\mathrm{OD}_{600}, \lambda=600 \mathrm{~nm}\right.$ absorbance filter, 10 flashes) and shaking ( 5 s, orbital shaking, high speed). For each experiment, the fluorescence intensity $(\mathrm{FI})$ and $\mathrm{OD}_{600}$ data was corrected by subtracting the values of absorbance and fluorescence backgrounds.

\subsection{Scanning Electron Microscopy}

A $5 \mathrm{~mL}$ bacterial suspension $\left(\mathrm{OD}_{600}=0.2\right)$ was mixed with different concentrations of MDP DA30 chitosan $(2.95,5.88,8.79,28.7$, and $226.6 \mu \mathrm{g} / \mathrm{mL})$. The mixture was incubated at $4{ }^{\circ} \mathrm{C}$ and $100 \mathrm{rpm}$ shaking for one hour. Subsequently, each mixture was filtered through a polycarbonate membrane with $1.2 \mu \mathrm{m}$ track-etched pores mounted onto a funnel assembly connected to a vacuum pump. After filtering, the material was fixed in $2.5 \%$ aqueous glutaraldehyde for $1 \mathrm{~h}$; then the membranes were washed with PBS once for 10 min after fixing. Finally, the samples were dehydrated through a graded series of aqueous ethanol solutions $(10,30,50,70,90$, and 100\% v/v) for 10 min of each and kept in a sealed desiccator until complete dehydration. All samples were sputter-coated with gold and imaged using a scanning electron microscope (SEM, S-3000N, Hitachi, Tokyo, Japan). Micrographs were recorded digitally. 


\subsection{Statistical Analysis}

Statistical analysis was carried out using Prism v6.0c (GraphPad Software Inc., La Jolla, CA, USA). All experiments were performed in triplicates to validate reproducibility and the $P$ values were calculated statistically by Student's $t$-test. Values were expressed as mean \pm standard deviation (SD). Comparison analyses were performed between tests and controls.

\section{Results}

The ten chitosans with varying $M_{w}$ and DA investigated in this study (Table 1) were part of the series of samples that we have addressed in the frame of the Nano3Bio EU project [34]. Both DA and $M_{w}$ of the samples span a very wide range. This range of DA and $M_{w}$ envelops well the most common properties of commercial chitosans. In Table 1 , one column gives the concentration $(\mu \mathrm{g} / \mathrm{mL}) \mathrm{of}$ each chitosan corresponding with a constant equivalent molar charge $\left[\mathrm{NH}_{3}{ }^{+}\right]$concentration of $0.389 \mathrm{mM}$. We have performed the antibacterial activity assays by controlling the charge-equivalent concentration, rather than the mass per volume one. Of note, two chitosan samples were not included in the experimental evaluation of their DA, namely LDP DA 20 and LDP DA 30. However, in Table 1, we have added a column with the estimated DA, as calculated from the stoichiometry of the $N$-acetylation reaction. Hence, the experimental DA values of these samples can be assumed to lie close to the expected ones, in keeping with the rest of experimentally measured samples. Also, we were unable to determine the $M_{w}$ and $I_{p}$ for the sample with code LDP DA 60. However, given that this sample corresponds to the same series of $N$-acetylated chitosans that were prepared by $N$-acetylation from the same depolymerized chitosan sample of low DA $(1.6 \%)$, we are confident that the degree of polymerization of this material lies close to the rest of the samples in the 'LDP' series. Despite the fragmented data for these three samples, we decided to include them in the study.

\subsection{Antibacterial Assay}

Two distinct methods were used to investigate the antibacterial activity of the different chitosans, namely by measuring the growth rate during the exponential phase from the time evolution of the optical density $\left(\mathrm{OD}_{600}\right)$, and by a plating assay to estimate the number of viable bacteria $(\mathrm{CFU} / \mathrm{mL})$. Notice in Figure 1a that bacteria treated with an equivalent equimolar charge concentration $(0.389 \mathrm{mM})$ of the different chitosans subjected to a first incubation cycle in M9 culture medium were able to grow (albeit with differences) upon re-seeding and incubated for a second cycle. This is taken as demonstrated diagnostic evidence of a predominant bacteriostatic, rather than bactericidal, effect for all tested chitosans. Of note though, regardless of the $M_{w}$, only chitosans with DA $\sim 12 \%$ significantly reduced the relative growth rate by $\sim 50 \%$. In turn, the agar gel plating assay (Figure $1 \mathrm{~b}$ ) revealed that exclusively MDP and LDP chitosans of low DA $(\mathrm{DA}=12 \%)$ reduced the number of CFUs per $\mathrm{mL}$. This reduction exhibited a dose-dependent effect, as we noticed upon treatment with two different chitosan doses $(0.389$ and $0.778 \mathrm{mM})$. Also, LDP DA12 chitosan was more effective than MDP DA12 as revealed by the agar plate assay. Interestingly, the highest DA chitosan sample (LDP DA60, DA 69\%), also reduced the plate count number in a dose-dependent manner with respect to the control. None of the other chitosans exhibited antibacterial activity, as confirmed in both assays. 


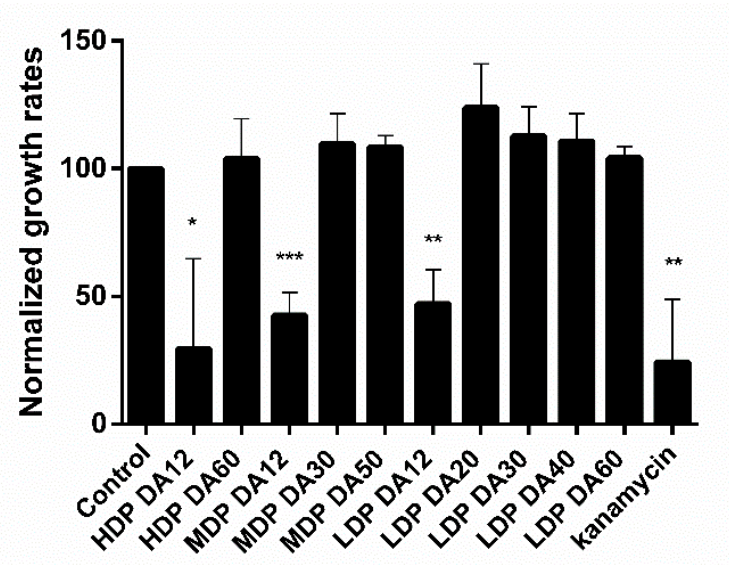

(a)

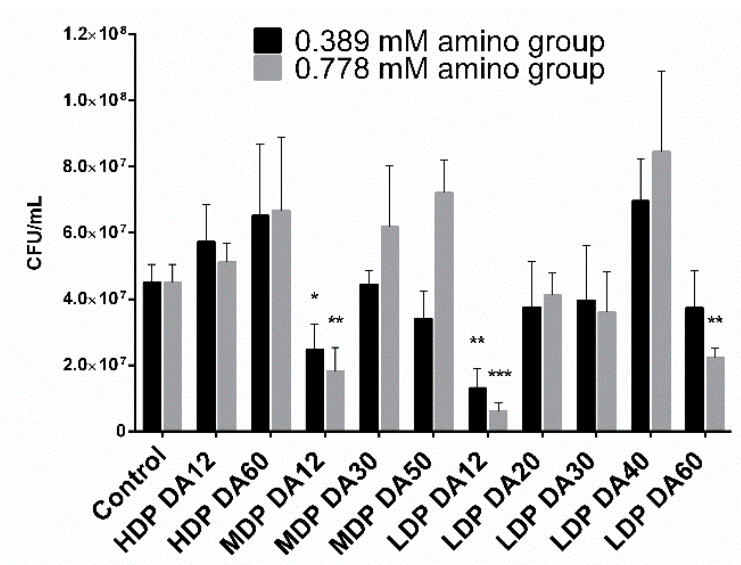

(b)

Figure 1. (a) Relative growth rate after re-seeding of E. coli TOP10 bacteria treated with identical charge-equivalent molar concentrations $(0.389 \mathrm{mM})$ of chitosans of varying degree of acetylation and polymerization (for sample details, refer to Table 1 ). In the first cycle, the bacteria were incubated for 2:38 $\mathrm{h}$ in M9 medium at $37{ }^{\circ} \mathrm{C}$, whereas in the second cycle, an aliquot of the bacterial culture was re-seeded in fresh M9 medium and incubated for further 2:38 h. Absorbance as measured at $\lambda=600 \mathrm{~nm}$ as a function of the chitosan concentration added to the M9 medium with E. coli. One (negative) control corresponds to bacteria cultivated in M9 medium, while the other (positive) control was kanamycin $(50 \mu \mathrm{g} / \mathrm{mL})$ added to the M9 medium. (b) Antibacterial effect of chitosans of varying degree of acetylation and $M_{w}$ with two different amino group concentrations $(0.389$ and $0.778 \mathrm{mM})$ on the growth of E. coli TOP10 incubated in a 96-well-plate at $37^{\circ} \mathrm{C}$ and $100 \mathrm{rpm}$ for $1 \mathrm{~h}$ as tested in a CFU agar plate assay. The control corresponds to untreated bacteria $\left({ }^{*} p<0.05,{ }^{* *} p<0.01\right.$ and ${ }^{* * *} p<0.001$; values represent average \pm standard deviation (SD), $n \geq 3$; three technical replicates).

\subsection{Escherichia coli Top10 Quorum Sensing Biosensor Assay with Different Concentrations of Chitosan}

Based on the results of the antibacterial activity assays above, we selected one of the chitosan samples that did not exhibit any effect on growth rate, namely chitosan MDP DA30 (DA 42\% and $\left.M_{w} 115 \mathrm{kDa}\right)$, to further investigate its QS inhibition activity. To this end, we evaluated the effect of varying concentrations of this chitosan $(1.25$ to $50 \mu \mathrm{g} / \mathrm{mL})$ on the QS response of the E. coli TOP10 strain. Given that the QS system operates with AHL concentrations orders of magnitude lower than those tested for chitosan in the antimicrobial assays, the concentrations of chitosan tested in this assay were 160- to 4-fold lower than those tested in the antibacterial assays. The bacterial strain is the same one that we have used in parallel studies [26-30,33]. It is a green fluorescent protein (GFP) reporter that does not synthesize its own AHL, namely $3 \mathrm{OC}_{6} \mathrm{HSL}$, and responds by producing GFP upon exogenous addition of extremely low concentrations of $3 \mathrm{OC}_{6} \mathrm{HSL}(<1 \mathrm{nM})$.

Figure $2 \mathrm{a}, \mathrm{c}$ illustrate the influence of varying concentrations of chitosan on the evolution and end-point values of $\mathrm{OD}_{600}$, respectively. Close inspection of Figure 2a reveals that the addition of chitosan in low doses of 1.25 and $2.5 \mu \mathrm{g} / \mathrm{mL}$ does not modify the growth curve with respect to the control. However, as the concentration of chitosan increases to $4.17 \mu \mathrm{g} / \mathrm{mL}$, a sudden rise in $\mathrm{OD}_{600}$ occurs at time point $110 \mathrm{~min}$. The same effect occurs also with 8.33 and $12.5 \mu \mathrm{g} / \mathrm{mL}$ of chitosan, though at later onset times, namely $\sim 150$ and $\sim 180 \mathrm{~min}$, respectively. Upon addition of even greater concentrations of chitosan ( 25 and $50 \mu \mathrm{g} / \mathrm{mL}$ ), the rise in $\mathrm{OD}_{600}$ is no longer appreciated and the traces mirror those of the control. The results after $350 \mathrm{~min}$ ('end point') summarized in Figure 2c illustrate that up to a concentration of $12.5 \mu \mathrm{g} / \mathrm{mL}$, chitosan leads to an increase of the final $\mathrm{OD}_{600}$ values. Beyond this concentration, there is no effect on the bacterial growth. Figure $2 b$ depicts the fluorescence intensity data corresponding to the same time points of the $\mathrm{OD}_{600}$ measurements during the microtiter plate assay. A detailed inspection of the fluorescence intensity traces reveals a rather peculiar dependence 
of the GFP expression on the concentration of added chitosan. At low concentrations of chitosan, namely $1.25-4.17 \mu \mathrm{g} / \mathrm{mL}$, the fluorescence intensity is severely attenuated after $120 \mathrm{~min}$, and attains a minimum value at $2.5-4.17 \mu \mathrm{g} / \mathrm{mL}$. At greater concentrations of chitosan $(\geq 8.33 \mu \mathrm{g} / \mathrm{mL})$, the intensity increases until almost the same value as the untreated control. Figure $3 \mathrm{~d}$ shows the fluorescence intensity end-point values that clearly summarize the results. Notice that the minimal fluorescence intensity was assessed at a chitosan concentration of $2.5 \mu \mathrm{g} / \mathrm{mL}$.

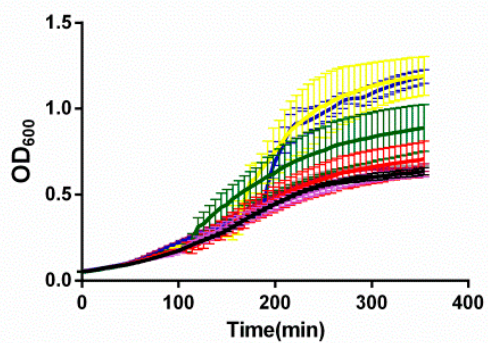

(a)

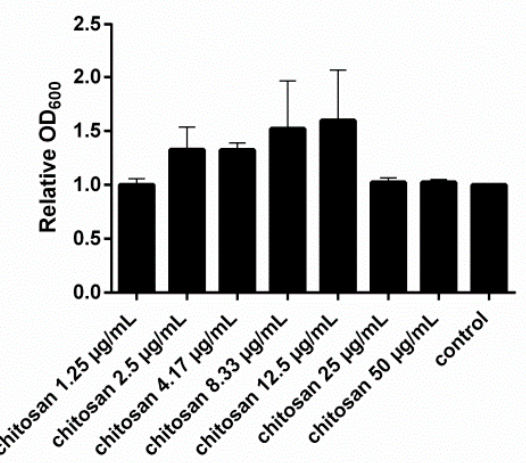

(c)
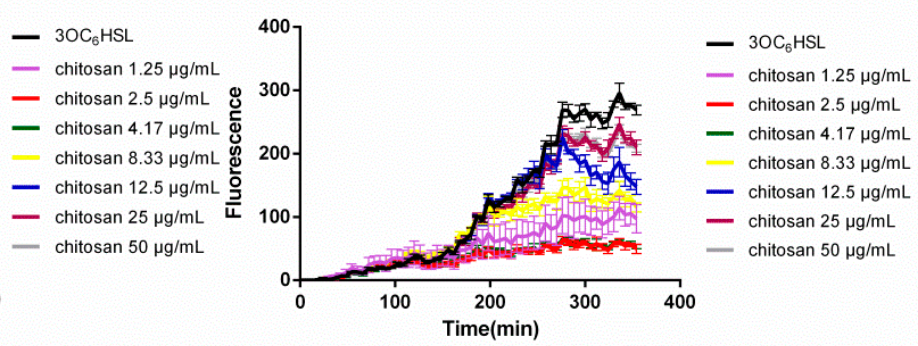

(b)

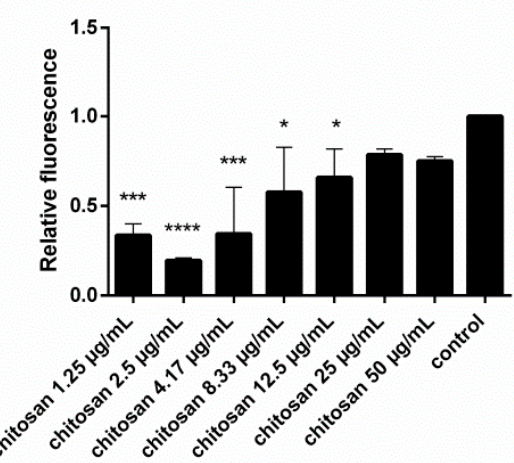

(d)

Figure 2. (a) Effect of varying concentrations of chitosan MDP DA30 (DA $42 \%$ and $M_{w} 115 \mathrm{kDa}$ ) on the growth of E. coli TOP10 as measured by assessing the absorbance at $\lambda=600 \mathrm{~nm}$; (b) Effect of different concentrations of chitosan on bacterial fluorescence intensity; (c) Effect of varying concentrations of chitosan on endpoint $\mathrm{OD}_{600}$ relative to the control, corresponding with the data shown in panel a; (d) Effect of varying concentrations of chitosan on fluorescence/ $\mathrm{OD}_{600}$ relative to the control, corresponding with the data shown in panel b; $3 \mathrm{OC}_{6}$ HSL concentration: $2.5 \times 10^{-10} \mathrm{M}\left({ }^{*} p<0.05{ }^{* *} p\right.$ $<0.01,{ }^{* * *} p<0.001$, and ${ }^{* * *} p<0.0001$; values represent average $\pm \mathrm{SD}, n \geq 3$; three technical replicates).

\subsection{Scanning Electron Microscopy Imaging of Escherichia coli Top10 Mixed with Different Concentrations of Chitosan}

With the aim of gleaning understanding regarding the observed effects of chitosan on the E. coli TOP10 strain, we recorded SEM images after incubating a fixed number of bacteria $\left(\mathrm{OD}_{600}=0.2\right)$ with varying concentrations of MDP DA30 chitosan $(2.95,5.88,8.79,28.7$, and $226.6 \mu \mathrm{g} / \mathrm{mL})$. Figure 3a shows the image of E. coli TOP10 bacteria alone that appear as isolated rods. However, upon addition of chitosan at concentrations $\leq 28.7 \mu \mathrm{g} / \mathrm{mL}$, bacteria invariably appear aggregated in conglomerates (Figure $3 \mathrm{~b}-\mathrm{e})$. At the highest concentration of chitosan $(226.6 \mu \mathrm{g} / \mathrm{mL})$ though, bacteria again appear as isolated entities (Figure 3f). Visual inspection of the bacterial suspensions upon addition of chitosan, also reflected that the turbidity of the suspensions was maximal between 8.79 and $28.7 \mu \mathrm{g} / \mathrm{mL}$ (see Figure S1). 

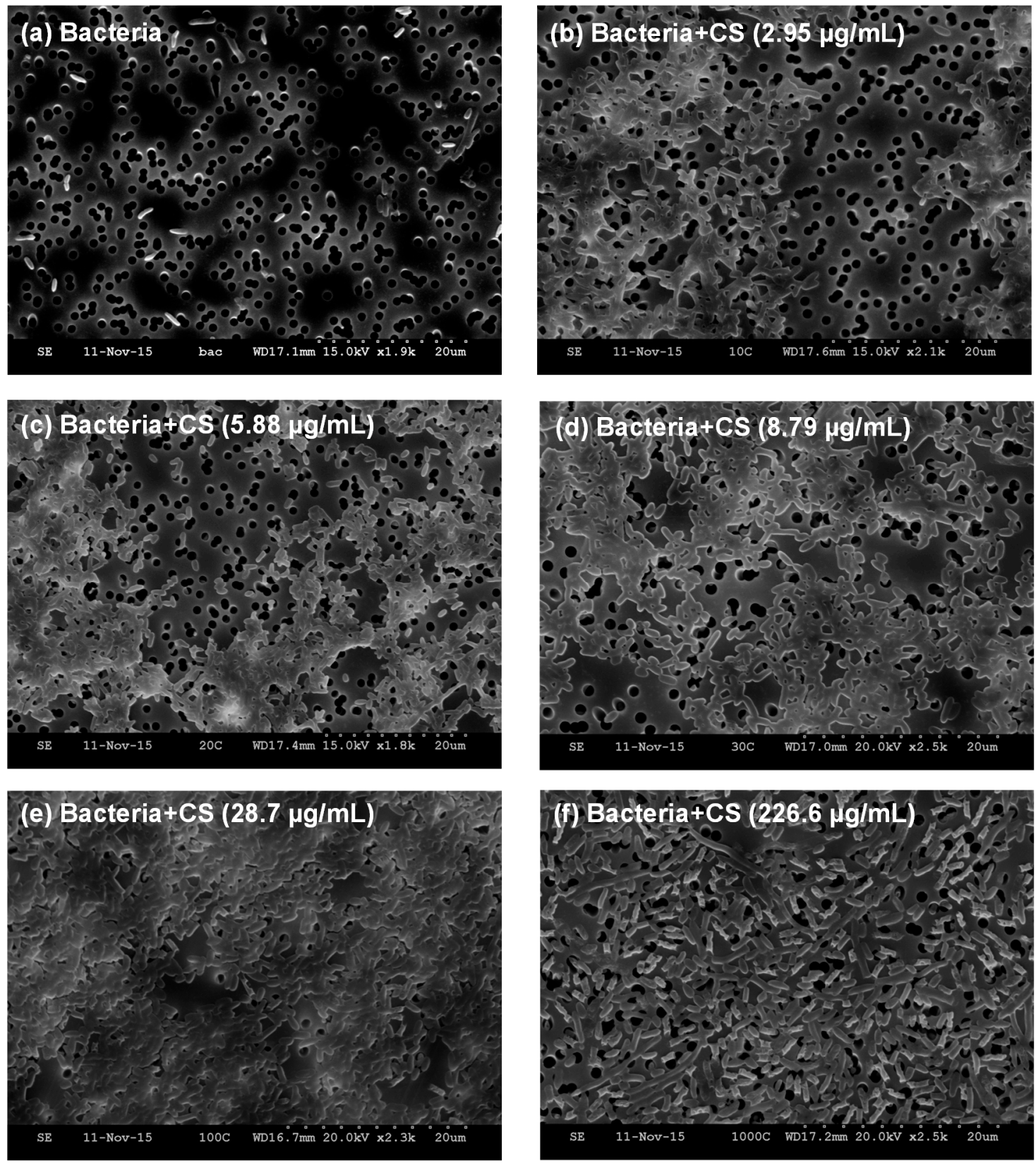

Figure 3. Scanning electron microscopy images of (a) E. coli TOP10 bacteria alone; and an equivalent number of bacteria $\left(\mathrm{OD}_{600}=0.2\right)$ mixed with varying concentrations of MDP DA30 chitosan, namely (b) $2.95 \mu \mathrm{g} / \mathrm{mL}$; (c) $5.88 \mu \mathrm{g} / \mathrm{mL}$; (d) $8.79 \mu \mathrm{g} / \mathrm{mL}$; (e) $28.7 \mu \mathrm{g} / \mathrm{mL}$; (f) $226.6 \mu \mathrm{g} / \mathrm{mL}$, after incubation at $4{ }^{\circ} \mathrm{C}$ and slight shaking for $1 \mathrm{~h}$, supported on track-etched polycarbonate membranes. Under these imaging conditions, bacteria appear as bright rod objects. Polycarbonate support appears as a gray background, and sharply-defined track-etched pores appear as dark circles of $\sim 1.2 \mu \mathrm{m}$ in diameter.

\section{Discussion}

The actual mode of action whereby chitosan exerts its antimicrobial activity is not fully understood yet. In the case of antibacterial activity, several hypotheses have been put forward to explain the mechanisms at play. One is related to the ability of the available $\mathrm{NH}_{3}{ }^{+}$groups in chitosan to bind to negatively charged proteins of the outer membrane of Gram-negative bacteria leading to imbalances of the internal osmotic equilibrium and/or leakage of proteinaceous and other intracellular constituents $[17,18]$. Another proposed mechanism argues that chitosan penetrates the cell membrane 
and binds to DNA or mRNA in the cytosol, thus interfering with protein synthesis $[4,5,9,35]$. It has also been proposed that a chitosan's mode of action would involve chelating trace elements leading to growth and metabolic arrest [5]. The antimicrobial activity of chitosan is known to depend on several factors either associated to the type of microorganism, the characteristics of the cell envelope, to intrinsic features of chitosan (e.g., DA, $M_{w}$, chelating capacity and hydrophilic/hydrophobic characteristics), or to environmental factors (e.g., $\mathrm{pH}$ of the medium, temperature, time) $[9,15]$.

In an attempt to examine in detail the influence of the charge density of chitosan (i.e., given directly by the DA), in the present work, we applied the same $\left[\mathrm{NH}_{3}{ }^{+}\right]$charge-equivalent concentration of chitosans of varying DA and $M_{w}$. Notice that in these series of experiments to assess identical charge-equivalent concentrations, the greater the DA, the greater was the added mass concentration (Table 1); and yet only the chitosans of lower DA (i.e., dosed at the lowest mass concentrations) exhibited antibacterial activity, as evident by the growth rate in liquid culture and in the agar plate colony number counts. Regarding the $M_{w}$, in the case of growth rate studies, the three chitosans of low DA LDP DA12, MDP DA12, and HDP DA12 had a strong effect on suppressing growth. However, in the plating assays, carried out in agar gels, only the medium and low $M_{w}$ chitosans reduced the number of CFU/mL.

A possible explanation to the apparently discrepant results between the two assays, based purely on physical grounds, could be differences in the diffusion rates of chitosan when dissolved either in the liquid or in the agar gel media for the growth rate and plating assays, respectively. In the former case, the chitosans in solution are able to diffuse freely and interact with bacteria, whereas in the agar plate assay, presumably only the chitosans of low $M_{w}$ were able to diffuse through the agar's dense molecular gel network and interact with bacteria, while the high $M_{w}$ was not. This is consistent with the fact that LDP DA12 chitosan, of the lowest $M_{w}$, had stronger activity than that of MDP DA 12. Also, these results are in overall agreement with previous studies documenting that chitosans of low $M_{w}$ exhibit stronger antibacterial activity due to their greater mobility and amenability to interact with the cell membrane surface [4,35]. This could be explained as the consequence of stronger electrostatic interactions between charged $\mathrm{NH}_{3}{ }^{+}$groups in deacetylated D-glucosamine and the bacterial cell membrane.

In previous studies, it has been suggested that the low antibacterial effect of chitosans of high DA is the result of greater inter-chain interactions due to H-bonds in addition to the hydrophobic character of the acetyl group in $N$-acetyl glucosamine, thus leading to a more densely overlapping coiled conformation. Those interactions have been suggested to inhibit the high DA chitosan binding to the bacterial cell walls [2,7]. We noticed that chitosan LDP DA 60 (DA 69\%) also reduced the plate count number in a dose-dependent manner. However, this same chitosan had no effect on growth rate in the liquid suspension assay. We do not have a convincing explanation for this result at present, particularly because the other chitosans of high DA, namely LDP DA 30 (DA 30\% $M_{w} 37 \mathrm{kDa}$ ) and LDP DA 40 (DA $44 \% M_{w} 58 \mathrm{kDa}$ ), did not reduce the number of viable bacteria.

Contrary to our expectations, only the chitosan of lower DA had a consistent effect on arresting the bacterial growth, even when the bacteria were treated with identical doses of charge-equivalent chitosan samples. From this experiment, it stands to reason that not only the effective amount of charged $\mathrm{NH}_{3}{ }^{+}$groups in the respective chitosan is what determines the antibacterial effect of chitosan, but that other structural features are also at play. Otherwise, a similar antibacterial activity would have been exhibited by all chitosans, when the equivalent concentration of charged $\mathrm{NH}_{3}{ }^{+}$was given to the bacteria. Whether a minimum block length of contiguous deacetylated D-glucosamine residues in chitosan is needed for the interaction with the bacterial cell surface has yet to be established. This would resemble a highly cooperative binding process (i.e., a minimal number of contiguous $N$-glucosamine or $N$-acetyl-glucosamine residues needed for binding). Moreover, the pattern of acetylation (PA) that might vary from block over random to an alternating pattern should also have significant impact on biological and physicochemical activity of the specific chitosan, seeing as the distribution of the acetyl group along the chitosan chain probably also affects the chitosan conformation and the ability to 
attach to the bacterial membrane [2,36,37]. Ongoing studies in our laboratories are currently testing the validity of these proposals using well-characterized chitosan oligomers.

For our further QS inhibition experiments, we selected only one chitosan that had no antibacterial activity, namely sample MDP DA 30 (DA $42 \%$ and $M_{w} 115 \mathrm{kDa}$ ). In the QS inhibition studies, both the evolution of $\mathrm{OD}_{600}$ and fluorescence intensity were recorded upon treating the bacteria with varying concentrations of chitosan $(1.25$ to $50 \mu \mathrm{g} / \mathrm{mL})$. The $\mathrm{OD}_{600}$ traces confirmed that this chitosan did not reduce the growth rate with respect to the control. However, sudden increases in $\mathrm{OD}_{600}$ were observed at three concentrations, namely $4.17,8.33$, and $12.5 \mu \mathrm{g} / \mathrm{mL}$. In parallel studies [26,38,39], we have observed very similar 'bumps' in the growth curves $\left(\mathrm{OD}_{600}\right)$ upon addition of an increasing number of chitosan-coated nanocapsules to the same E. coli strain as in this study. The appearance of such sudden 'bumps' observed in the growth traces can be explained as the consequence of attaining specific chitosan/bacteria ratios that result in the aggregation of bacteria, and thus in the sudden increase in $\mathrm{OD}_{600}$ values. Our SEM results are consistent with this explanation. In the case of chitosan-based nanocapsules [26], we have found that there is an optimal ratio of nanocapsules per bacterium at which the electrical charge of both is fully compensated (i.e., the $\zeta$-potential is $\sim 0$ ). At this so-called 'stoichiometric' ratio, the bacteria form large conglomerates and aggregation is maximal, with the behavior dependent on material concentration and cell density. Interestingly, the 'bumps' were only observed for three concentration ratios. It seems that only in these cases was the optimal stoichiometric ratio hit in the course of growth. At lower or greater concentrations, this optimal ratio was not attained, either because a defect or surplus of chitosan was present.

The MDP DA30 chitosan was found to have the capacity to inhibit QS as detected in the E. coli TOP10 strain, particularly when dosed at concentrations of 1.25 to $4.17 \mu \mathrm{g} / \mathrm{mL}$. At greater doses, the QS inhibition was less accentuated. The doses of maximal QS inhibition coincide closely with those at which the 'bumps' in the growth traces appear. Hence, it seems reasonable to argue that the inhibition of QS is the result of the maximum in bacterial agglomeration, which results in the retardation of the diffusion of $3 \mathrm{OC}_{6} \mathrm{HSL}$ into the cytosol, and hence in the attenuation of GFP expression. The SEM images recorded after incubation of bacteria with varying concentrations of chitosan show that substantial bacterial aggregation occurs when chitosan is added at low concentrations (Figure $3 b-e$ ). These results are in full agreement with the results recorded in the QS inhibition assays, namely with the occurrence of 'bumps' in $\mathrm{OD}_{600}$ growth traces and with the greatest attenuation in QS activity. However, when chitosan is added at highest concentrations, bacteria appear as isolated specimens (Figure 3f). In this case, we reasoned that the high concentration of chitosan leads to an excess of net positive charge at the bacterial surface, so as to prevent their aggregation [5].

\section{Conclusions}

Taken together, our results demonstrated that fully characterized chitosans of low DA $(\leq 12 \%)$ have a predominantly bacteriostatic activity rather than bactericidal one. Strikingly, only chitosans with DA $12 \%$ exhibited this activity, even when all chitosans were applied at the same net molar charge-equivalent concentration. Structural features of chitosans-such as hydrogen bonding, hydrophobic interactions, and possibly cooperative binding effects-might be determinant in defining the antibacterial activity of chitosans and mechanisms at play still need further elucidation. The validity of the present findings is yet to be demonstrated for other bacterial families, including other Gram-negative but also Gram-positive species. Structural differences in the bacterial envelope at the molecular level of each are likely to be essential to the specific mode of action of different chitosans. Our work has enabled us also to identify chitosans with no antibacterial activity, even when dosed at molar charge equivalent concentrations identical to bacteriostatic chitosans of low DA. We demonstrated that one of these chitosans (DA $42 \%$ and $M_{w} 115 \mathrm{kDa}$ ) when dosed at low concentrations $(2.5 \mu \mathrm{g} / \mathrm{mL}$, i.e., $\sim 50$-fold lower concentrations than for the antimicrobial assays), has QS inhibition activity. This might be attributed to maximal bacterial agglutination observed at such low doses. By contrast, greater doses of chitosan lead to attenuation of the QS inhibition effect. We are fully aware that the present work did 
not address the inhibition of bacterial biofilm formation, which might be also at play in controlling bacterial aggregation, driven by secretion of exo-polysaccharides and other virulent traits under QS regulation. This could be the subject of future studies.

We anticipate a high practical relevance to these findings, particularly in guiding the choice and dose of a given chitosan for applications-such as in food, wine making, water treatment, and downstream processing, among others-which are yet to be fully realized.

Supplementary Materials: The following are available online at http:/ /www.mdpi.com/2218-273X/8/3/87/s1.

Author Contributions: F.M.G. and X.Q. conceived and designed the study; J.E. and X.Q. performed the experiments and analyzed the data; X.Q. and F.M.G. interpreted the results and wrote the paper.

Funding: This research was funded by the Deutsche Forschungsgemeinschaft, grant number: GRK 1549 and the APC was funded by Ideas: European Research Council: FP7 613931. The authors acknowledge financial support by the Open Access Publication Fund of the Westfälische Wilhelms-Universität Münster.

Acknowledgments: X.Q. was recipient of a fellowship from China Scholarship Council. We acknowledge support from D.F.G., Germany (Project GRK 1549 International Research Training Group 'Molecular and Cellular GlycoSciences'); the research leading to these results has also received funding from the European Union's Seventh Framework Programme for research, technological development and demonstration under grant agreement no. 613931. We are also indebted to Celina Vila for the E. coli TOP10 QS biosensor strain and to Antje von Schaewen for generous access to the Safire Tecan-F129013 Microplate Reader.

Conflicts of Interest: The authors declare no conflict of interest.

\section{References}

1. Raafat, D.; von Bargen, K.; Haas, A.; Sahl, H.G. Insights into the Mode of Action of Chitosan as an Antibacterial Compound. Appl. Environ. Microbiol. 2008, 74, 3764-3773. [CrossRef] [PubMed]

2. Rinaudo, M. Chitin and chitosan: Properties and applications. Prog. Polym. Sci. 2006, 31, 603-632. [CrossRef]

3. Tokura, S.; Ueno, K.; Miyazaki, S.; Nishi, N. Molecular Weight Dependent Antimicrobial Activity by Chitosan. In New Macromolecular Architecture and Functions; Kamachi, M., Nakamura, A., Eds.; Springer: Berlin/Heidelberg, Germany, 1997; Volume 120, pp. 1-9. ISBN 978-3-642-80289-8.

4. Benhabiles, M.S.; Salah, R.; Lounici, H.; Drouiche, N.; Goosen, M.F.A.; Mameri, N. Antibacterial activity of chitin, chitosan and its oligomers prepared from shrimp shell waste. Food Hydrocoll. 2012, 29, 48-56. [CrossRef]

5. Rabea, E.I.; Badawy, M.E.-T.; Stevens, C.V.; Smagghe, G.; Steurbaut, W. Chitosan as antimicrobial agent: Applications and mode of action. Biomacromolecules 2003, 4, 1457-1465. [CrossRef] [PubMed]

6. Kong, M.; Chen, X.; Xing, K.; Park, H.J. Antimicrobial properties of chitosan and mode of action: A state of the art review. Int. J. Food Microbiol. 2010, 144, 51-63. [CrossRef] [PubMed]

7. Goy, R.C.; Morais, S.T.B.; Assis, O.B.G. Evaluation of the antimicrobial activity of chitosan and its quaternized derivative on E. coli and S. aureus growth. Rev. Bras. Farmacogn. 2016, 26, 122-127. [CrossRef]

8. No, H.K.; Park, N.Y.; Lee, S.H.; Meyers, S.P. Antibacterial activity of chitosans and chitosan oligomers with different molecular weights. Int. J. Food Microbiol. 2002, 74, 65-72. [CrossRef]

9. Devlieghere, F.; Vermeulen, A.; Debevere, J. Chitosan: Antimicrobial activity, interactions with food components and applicability as a coating on fruit and vegetables. Food Microbiol. 2004, 21, 703-714. [CrossRef]

10. Azuma, K.; Osaki, T.; Minami, S.; Okamoto, Y. Anticancer and anti-inflammatory properties of chitin and chitosan oligosaccharides. J. Funct. Biomater. 2015, 6, 33-49. [CrossRef] [PubMed]

11. Sogias, I.A.; Williams, A.C.; Khutoryanskiy, V.V. Why is Chitosan Mucoadhesive? Biomacromolecules 2008, 9, 1837-1842. [CrossRef] [PubMed]

12. Menchicchi, B.; Fuenzalida, J.P.; Bobbili, K.B.; Hensel, A.; Swamy, M.J.; Goycoolea, F.M. Structure of Chitosan determines its interactions with mucin. Biomacromolecules 2014, 15, 3550-3558. [CrossRef] [PubMed]

13. Nagamoto, T.; Hattori, Y.; Takayama, K.; Maitani, Y. Novel chitosan particles and chitosan-coated emulsions inducing immune response via intranasal vaccine delivery. Pharm. Res. 2004, 21, 671-674. [CrossRef] [PubMed]

14. Roy, K.; Mao, H.Q.; Huang, S.K.; Leong, K.W. Oral gene delivery with chitosan-DNA nanoparticles generates immunologic protection in a murine model of peanut allergy. Nat. Med. 1999, 5, 1-5. [CrossRef] [PubMed] 
15. Verlee, A.; Mincke, S.; Stevens, C.V. Recently developments in antibacterial and antifungal chitosan and its derivatives. Carbohydr. Polym. 2017, 164, 268-283. [CrossRef] [PubMed]

16. Luis, E.; Paz, C.D.; Resin, A.; Howard, K.A.; Sutherland, D.S.; Wejse, P.L. Antibacterial effect of chitosan nanoparticles in Streptococcus mutans biofilms. Appl. Environ. Microbiol. 2011, 77, 3892-3895.

17. Jeon, S.J.; Oh, M.; Yeo, W.-S.; Galvão, K.N.; Jeong, K.C. Underlying mechanism of antimicrobial activity of chitosan microparticles and implications for the treatment of infectious diseases. PLoS ONE 2014, 9, e92723. [CrossRef] [PubMed]

18. Helander, I.M.; Nurmiaho-Lassila, E.-L.; Ahvenainen, R.; Rhoades, J.; Roller, S. Chitosan disrupts the barrier properties of the outer membrane of Gram-negative bacteria. Int. J. Food Microbiol. 2001, 71, 235-244. [CrossRef]

19. Qi, L.; Xu, Z.; Jiang, X.; Hu, C.; Zou, X. Preparation and antibacterial activity of chitosan nanoparticles. Carbohydr. Res. 2004, 339, 2693-2700. [CrossRef] [PubMed]

20. Ouattara, B.; Simard, R.E.; Piette, G.; Begin, A.; Holley, R.A. Inhibition of surface spoilage bacteria in processed meats by application of antimicrobial films prepared with chitosan. Int. J. Food Microbiol. 2000, 62, 139-148. [CrossRef]

21. Blair, J.M.A.; Webber, M.A.; Baylay, A.J.; Ogbolu, D.O.; Piddock, L.J.V. Molecular mechanisms of antibiotic resistance. Nat. Rev. Microbiol. 2014, 13, 42-51. [CrossRef] [PubMed]

22. Fuqua, C.; Parsek, M.R.; Greenberg, E.P. Regulation of gene expression by cell to cell communication: Acyl-homoserine lactone quorum sensing. Annu. Rev. Genet. 2001, 35, 439-468. [CrossRef] [PubMed]

23. Waters, C.M.; Bassler, B.L. Quorum sensing: Cell-to-cell communication in bacteria. Annu. Rev. Cell Dev. Biol. 2005, 21, 319-346. [CrossRef] [PubMed]

24. Kociolek, M.G. Quorum-sensing inhibitors and biofilms. Antiinfect. Agents Med. Chem. 2009, 8, 315-326. [CrossRef]

25. Costa, E.M.; Silva, S.; Pina, C.; Tavaria, F.K.; Pintado, M. Antimicrobial Effect of Chitosan against Periodontal Pathogens Biofilms. SOJ Microbiol. Infect. Dis. 2014, 2, 1-6.

26. Qin, X.; Engwer, C.; Desai, S.; Vila-Sanjurjo, C.; Goycoolea, F.M. An investigation of the interactions between a bacterial quorum-sensing biosensor and chitosan-based nanoparticles. Colloid Surf. B 2017, 149, 358-368. [CrossRef] [PubMed]

27. Omwenga, E.O.; Hensel, A.; Shitandi, A.; Goycoolea, F.M. Chitosan nanoencapsulation of flavonoids enhances their quorum sensing and biofilm formation inhibitory activities against an E. coli Top 10 biosensor. Colloid Surf. B 2018, 164, 125-133. [CrossRef] [PubMed]

28. Qin, X.; Kräft, T.; Goycoolea, F.M. Chitosan encapsulation modulates the effect of trans-cinnamaldehyde on AHL-regulated quorum sensing activity. Colloid Surf. B 2018, 169, 453-461. [CrossRef] [PubMed]

29. Hao, N.T.; Goycoolea, F.M. Chitosan/cyclodextrin/TPP nanoparticles loaded with quercetin as novel quorum sensing inhibitors. Molecules 2017, 22, 1975. [CrossRef]

30. Omwenga, E.O.; Hensel, A.; Pereira, S.; Shitandi, A.A.; Goycoolea, F.M. Antiquorum sensing, antibiofilm formation and cytotoxicity activity of commonly used medicinal plants by inhabitants of Borabu sub-county, Nyamira County, Kenya. PLoS ONE 2017, 12, e0185722. [CrossRef] [PubMed]

31. Santos-Carballal, B.; Aaldering, L.J.; Ritzefeld, M.; Pereira, S.; Sewald, N.; Moerschbacher, B.M.; Götte, M.; Goycoolea, F.M. Physicochemical and biological characterization of chitosan-microRNA nanocomplexes for gene delivery to MCF-7 breast cancer cells. Sci. Rep. 2015, 5, 13567. [CrossRef] [PubMed]

32. Lavertu, M.; Xia, Z.; Serreqi, A.N.; Berrada, M.; Rodrigues, A.; Wang, D.; Buschmann, M.D.; Gupta, A. A validated ${ }^{1} \mathrm{H}$ NMR method for the determination of the degree of deacetylation of chitosan. J. Pharm. Biomed. Anal. 2003, 32, 1149-1158. [CrossRef]

33. Vila-Sanjurjo, C.; Engwer, C.; Qin, X.; Hembach, L.; Verdia-Cotelo, T.; Remunan-Lopez, C.; Vila-Sanjurjo, A.; Goycoolea, F.M. A single intracellular protein governs the critical transition from an individual to a coordinated population response during quorum sensing: Origins of primordial language. bioRxiv 2016. [CrossRef]

34. Nano3Bio.eu. Available online: www.nano3bio.eu (accessed on 16 September 2015).

35. Goy, R.C.; de Britto, D.; Assis, O.B.G. A review of the antimicrobial activity of chitosan. Polimeros 2009, 19, 241-247. [CrossRef]

36. Weinhold, M.X.; Sauvageau, J.C.M.; Kumirska, J.; Thöming, J. Studies on acetylation patterns of different chitosan preparations. Carbohydr. Polym. 2009, 78, 678-684. [CrossRef] 
37. Kumirska, J.; Weinhold, M.X.; Steudte, S.; Thöming, J.; Brzozowski, K.; Stepnowski, P. Determination of the pattern of acetylation of chitosan samples: Comparison of evaluation methods and some validation parameters. Int. J. Biol. Macromol. 2009, 45, 56-60. [CrossRef]

38. Vila-Sanjurjo, C.; Hembach, L.; Netzer, J.; Remuñán-López, C.; Vila-Sanjurjo, A.; Goycoolea, F.M. Covalently and ionically, dually crosslinked chitosan nanoparticles block quorum sensing and affect cell growth on a cell-density dependent manner. Submitted.

39. Vila-Sanjurjo, C.; David, L.; Remuñán-López, C.; Vila-Sanjurjo, A.; Goycoolea, F.M. Bacterial quorum quenching by sub-lethal levels of chitosan nanoparticles. Submitted.

2018 by the authors. Licensee MDPI, Basel, Switzerland. This article is an open access article distributed under the terms and conditions of the Creative Commons Attribution (CC BY) license (http://creativecommons.org/licenses/by/4.0/). 